\section{Synchronization of atmospheric indicators at the last stage of earthquake preparation cycle}

\author{
Sergey A. Pulinets, ${ }^{1}$ Lidia I. Morozova, ${ }^{2}$ \\ Ilya A. Yudin ${ }^{3}$
}

'Space Research Institute, Russian Academy of Sciences, Moscow; ${ }^{2}$ Trofimuk Institute of Petroleum Geology and Geophysics SB RAS, Novosibirsk; ${ }^{3}$ Research Institute of Aerospace Monitoring (AEROCOSMOS), Moscow, Russia

\begin{abstract}
We consider the dynamics of different parameters in the boundary layer of atmosphere and low level cloud structure around the time of three recent moderate and strong earthquakes: Virginia M 5.8 earthquake on August 232011 in USA, Van M 7.1 earthquake on October 232011 in Turkey, and Northwestern Iran M 6.4 earthquake on August 11, 2012, Iran. Using as indicators the water vapor chemical potential correction value, aerosol optical thickness, and linear cloud structures appearance we discovered their coherence in space and time within the time interval 3-5 days before the seismic shock. Obtained results are interpreted as synergetic result of the lithosphere-atmosphere-ionosphere coupling process.
\end{abstract}

\section{Introduction}

The meteorological anomalies observed at the latest stage of earthquake cycle within the area of earthquake preparation were reported from the ancient times. Mil'kis ${ }^{1}$ analyzing meteorological data in Middle Asia for the period 1895-1984 reported anomalously high air temperatures during the month (or season) when strong earthquakes happened in the region. The air temperatures observed within the earthquake preparation area were highest for the same month or season over the time period of several decades. The same results were obtained under analysis of meteorological data for several strong earthquakes in Mexico $^{2}$ and especially during the complex data analysis around the time of Colima 7.8 earthquake on January 21, 2003 in Mexico. ${ }^{3}$ The monthly mean January temperature at Manzanillo close to epicenter was highest for the last 50 years of observation (Figure 1A).
Similar study was repeated for Wenchuan earthquake using the meteorological parameters close to the position of the earthquake epicenter (Figure 1B). ${ }^{4}$

This increase of air temperature was accompanied by simultaneous air humidity drop. The authors demonstrate in the paper that variations of air temperature and humidity have local character and are not associated with the weather effect of meteorological origin. The most recent confirmation of this effect was obtained during multiparameter data analysis around the time of Tohoku M 9.0 earthquake on March 11, 2011 in Ouzounov. ${ }^{5}$ Taking into account that similar results were obtained for several hundred cases of earthquakes in different areas of the globe, we consider the air temperature increase few days before the strong earthquake well established. Physical mechanism which is able to explain the observed anomalies was proposed by Pulinets. ${ }^{6}$ Main driver of this process is the air ionization produced by radon and consequent process called ion induced nucleation (IIN) described by Kathmann. ${ }^{7}$ Pulinets $^{8}$ consider the chain of physical and plasma-chemical processes in the boundary layer of atmosphere which as a final result have formation of aerosol-size ion clusters and the local thermal effects are due to latent heat release during water vapor condensation on ions. If ion production rate is high enough, the nucleation has explosive character and leads to formation of aerosol-size particles similar to what we observe in cloud formation process under the action of galactic cosmic rays as it was shown by Swensmark. ${ }^{9}$ Aerosol formation before earthquakes was confirmed experimentally by monitoring the aerosol optical thickness (AOT) within the earthquake preparation area by AERONET network. One can find example of AOT monitoring around the time of San Simeon M 6.3 earthquake in California on December 21, 2003 in Pulinets. ${ }^{8}$ Thermal effects intensifying convection lift the condensation nucleus to the upper levels of troposphere helping to formation of so called Earthquake Clouds - linear cloud formations also observed few days before the seismic shock over the earthquake preparation area were demonstrated by Morozova. ${ }^{10}$

Synergetic effect of IIN was proposed by Pulinets $^{11}$ as a main driver for the chain atmospheric anomalies generation in the boundary layer of atmosphere. For self-organized processes is characteristic the existence of so called integral parameters showing the direction of the process development and its approaching to the critical state. As a candidate of such parameter the correction to the chemical potential of water vapor molecules attached to the ion during nucleation process $\Delta U$ was introduced by Pulinets ${ }^{6}$ and expressly specified by Boyarchuk (Eq.1):12
Correspondence: Sergey A. Pulinets, Space Research Institute, Russian Academy of Sciences, Moscow, Russia.

E-mail: pulse1549@gmail.com

Key words: earthquake preparation cycle, boundary layer, air ionization, ion induced nucleation.

Funding: the work was supported by a European Union Sevenths Framework Program (FP7/20017 2013) under Grant Agreement no. 263502PREEARTHQUAKES project: Processing Russian and European EARTH Observations for Earthquake Precursors Studies.

Contributions: the authors contributed equally.

Conflict of interests: the authors declare no potential conflict of interests. The paper reflects only the author's views and the European Union is not liable for any use that may be made of the information contained herein.

Received for publication: 30 May 2013.

Revision received: 13 June 2014.

Accepted for publication: 4 July 2014.

This work is licensed under a Creative Commons Attribution NonCommercial 3.0 License (CC BYNC 3.0).

(C) Copyright S.A. Pulinets et al., 2014

Licensee PAGEPress, Italy

Research in Geophysics 2014; 4:4898

doi:10.4081/rg.2014.4898

$$
\Delta U(\mathrm{eV})=5.810^{-10}\left(20 T_{g}+5463\right)^{2} \ln (100 / H),
$$

where $T_{g}$ is a ground air temperature, and $H$ is relative air humidity.

The increase of the water molecules chemical potential indicates the strength of nucleation process and can be used as indicator of earthquake approaching as it was shown by Boyarchuk. ${ }^{12}$ It is quite natural to expect that if the formation of aerosols is caused by IIN process, the increase of AOT and linear cloud structure formation should be synchronized with the increase of correction of the chemical potential $\Delta U$ as integral parameter. The validity of this statement will be checked in the present paper.

\section{Test cases}

We selected 3 earthquakes for which we were able to register all three parameters we want to use in our analysis: i) Van M 7.1 earthquake in Turkey on October 23 2011; ii) East Azerbaijan double shock M 6.4 and M 6.3 on August 11, 2012; and iii) Virginia M 5.8 earth- 
quake on August 23, 2011. We will compare different cases using similarity in tectonic structure (cases i and ii), and the same season but different climatic conditions (ii and iii). It is important to understand the influence of atmospheric conditions taking into account that we study the atmospheric anomalies associated with earthquake preparation process.

To calculate the correction to the chemical potential of water vapor molecules $\Delta U$ we used the meteorological data collected at the sites close to the earthquake epicenter from the WEB site Weather Underground (http://www. wunderground.com/). Aerosol optical thickness AOT was collected from the NASA AERONET database (http://aeronet. gsfc.nasa.gov/). Linear cloud structures were identified using the images from remote sensing satellites TERRA/MODIS and AQUA MODIS.

Taking into account that linear cloud anomalies (LCA) are not often used in publications dealing with precursory phenomena, it worth to devote attention to their determination and description. Selection of test cases is limited mainly by the data availability (especially by AERONET network), and close proximity of meteorological station to the epicenter.

\section{Linear cloud anomalies}

It is known from the literature ${ }^{8,13,14}$ that unusual linear cloud structures are often observed over the active tectonic zones, especially few days before the strong earthquakes. Activation of faults before earthquakes is accompanied by increase of radon emanation from the active tectonic faults. ${ }^{15,16}$ The variety of cloud anomalies over various parts of the region also characterizes the latest tectonic activity. The faults activity temporal dynamics is determined by LCA appearance using the sequential satellite images. These atmospheric cloud anomalies appear strictly over crustal faults in a period of tectonic stress accumula- tion. The persistence of LCA is an important weighting factor for its significance in a forecast. Anomaly can last from several minutes till several hours and even days. The simultaneous appearance of several LCA within the same satellite image over the earthquakeprone area increases the probability of the earthquake occurrence during that particular day. LCA in satellite images are narrow sharp linear boundaries of cloud masses, clearance canyons in cloud fields, or cloud banks against a cloudless sky. The interpretation of images during seismic processes showed that the LCA were manifested mainly in blurred cloud sharp linear boundaries and clearance canyons, ${ }^{17}$ and possible nature of bipolar appearance of LCA is proposed by Pulinets. ${ }^{8}$

LCA dislocation allows determining the geographical position of seismically active faults. According to their spatial and temporal dynamics it is possible to estimate the direction and the propagation velocity of the stresses in the earth's crust on local and global scales. On low
A
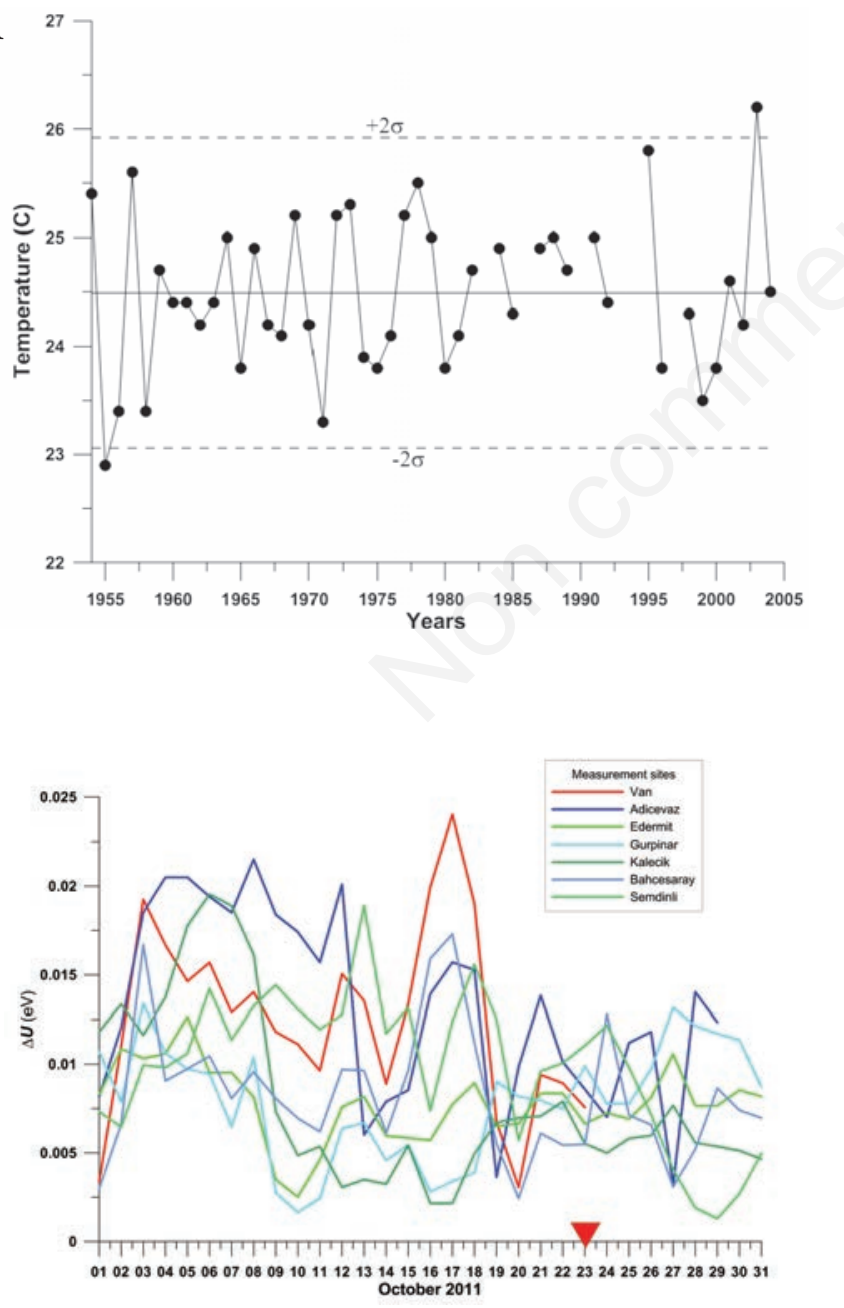

Figure 2. $\Delta U$ derived from meteorological measurements at different sites close to epicenter.

\section{B}

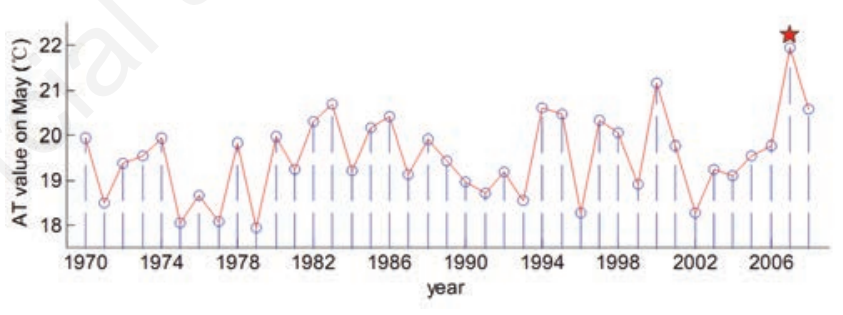

Figure 1. A) January monthly average air temperature at Manzanillo station (Mexico) for the period 1995-2005; B) May monthly average air temperature in the point $30^{\circ} \mathrm{N}, 105^{\circ} \mathrm{E}$ for the period 1979-2009.

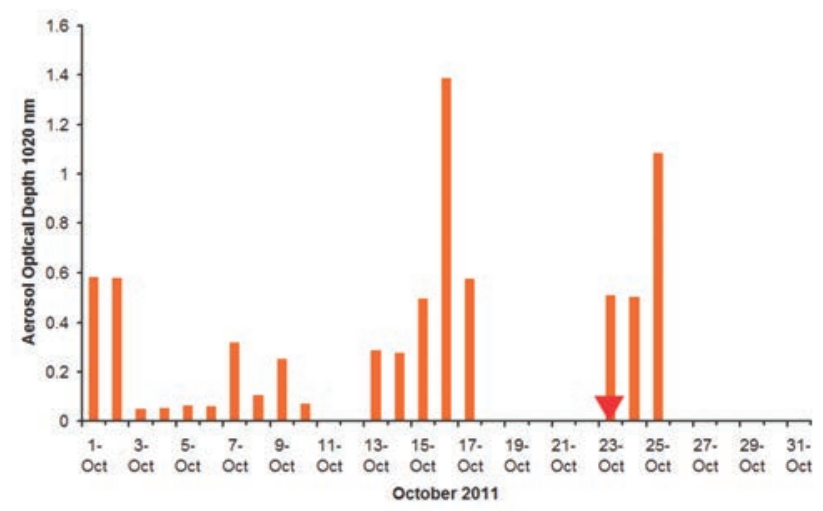

Figure 3. Aerosol optical thickness at the wavelength $1020 \mathrm{~nm}$ measured at AERONET IASBS station, October 2011. 
resolution images taken from the geostationary satellites the observed area comprise several tectonic plates, what allows tracing their interaction.

\section{Experimental data analysis}

For the case i) (Van earthquake) we calculated $\Delta U$ using meteorological measurements at several sites close to the earthquake epicenter (Figure 2).

Red line indicates $\Delta U$ variations in the point closest to the earthquake epicenter. The line is cut due to equipment failure after the main shock (red triangle). We see the absolute monthly maximum registered on 17 of October, 6 days before the main shock, and interval of increased $\Delta U$ parameter lasts from 15 till 18 of October. Variations at other sites also show the local maximum around 17 of October but not so pronounced as at Van.

AOT at the wavelength $1020 \mathrm{~nm}$ in the vicinity of epicenter (Figure 3) was acquired from AERONET station IASBS which is $400 \mathrm{~km}$ to the east from epicenter what is well inside the earthquake preparation zone determined by Dobrovolsky (Eq.2):18

$$
\mathrm{R}=10^{0.43 \mathrm{M}}
$$

One can see the sharp increase of AOT during days 14-17 of October (287-290 DOY). Gaps in measurements correspond to cloudy days.

From the measurements shown in Figures 2 and 3 we can conclude that intervals of $\Delta U$ and AOT anomalies practically coincide in time ( \pm 1 day). It is interesting to note that exactly within this time interval the linear cloud anomaly was registered by AQUA/MODIS during its daytime pass over the area of earthquake preparation which is presented in Figure 4.

Quasi-meridional cloud anomaly in the form of clearance canyon in a layer of high (cirrus) clouds ( $\mathrm{Ci}$, higher than $12 \mathrm{~km}$ ), which is existed near the earthquake's epicenter, appeared 5 days before shock, i.e. 18 of October (the canyon is marked in the figure by red line, and Van earthquake epicenter position - by red

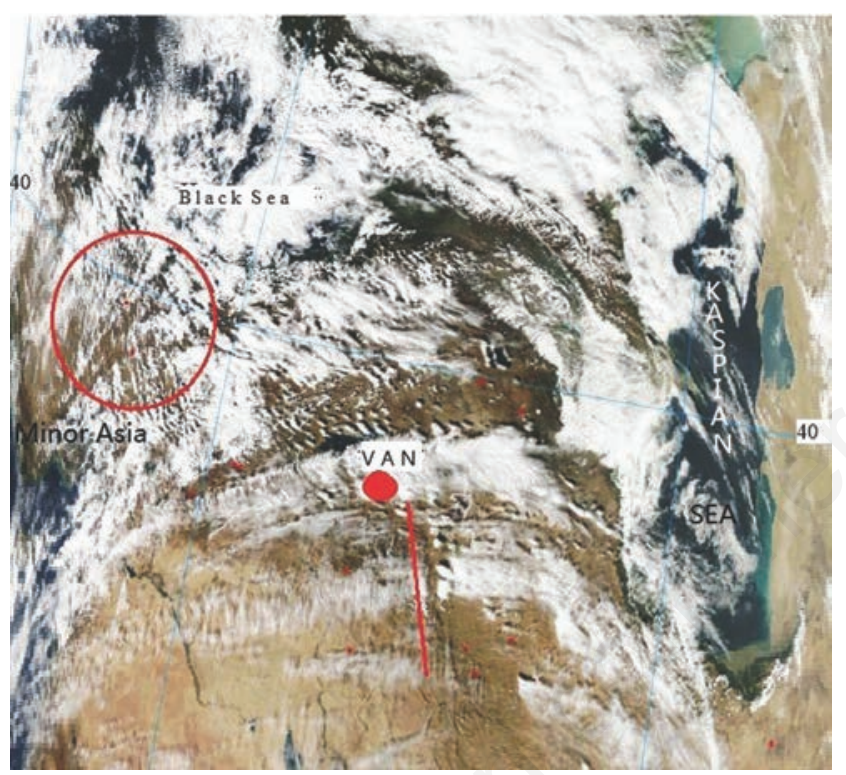

Figure 4. AQUA/MODIS satellite image taken on October 18, 2011 at 10.10 (UTC).

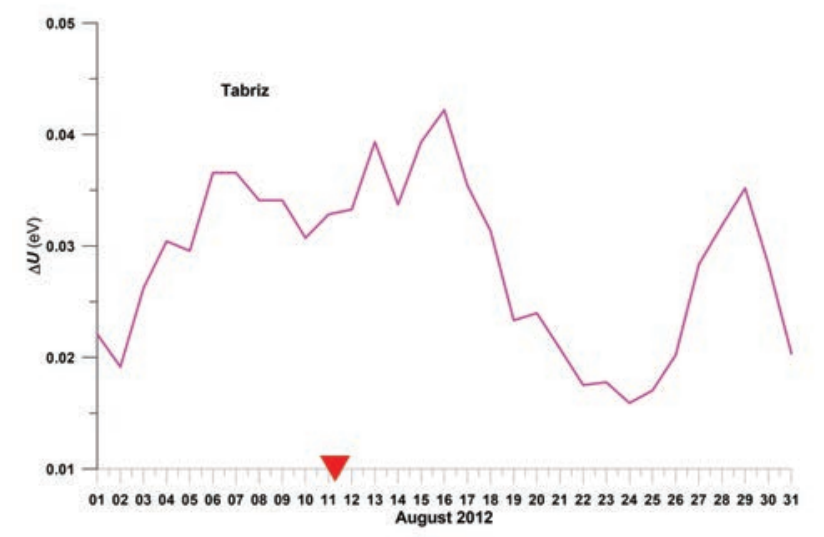

Figure 5. $\Delta U$ temporal variation for August 2012 in the vicinity of earthquake epicenter.
A

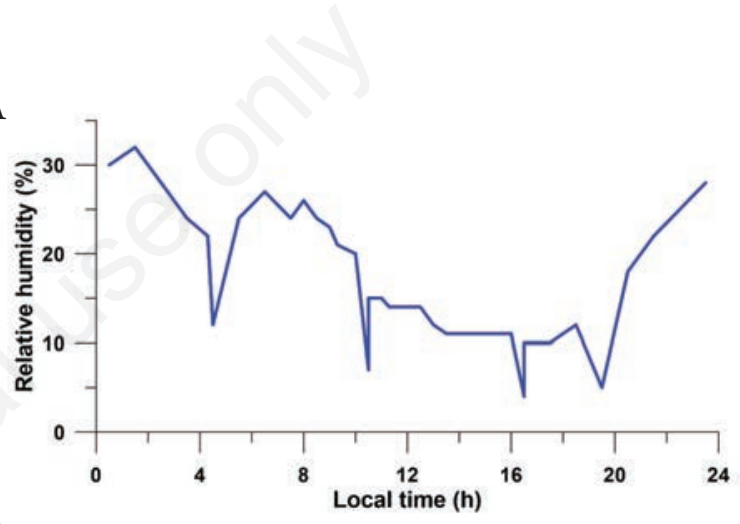

B

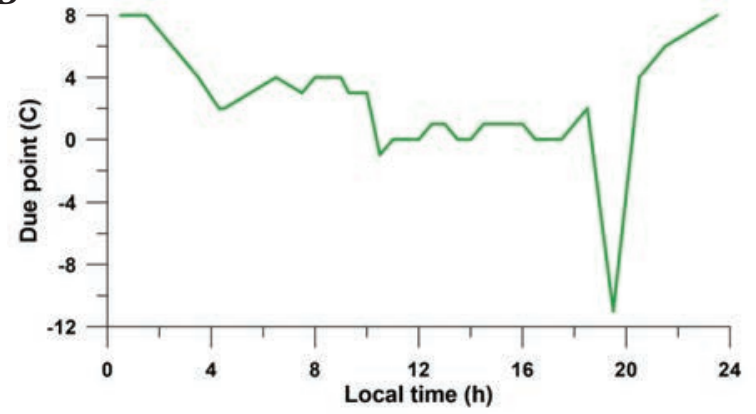

C

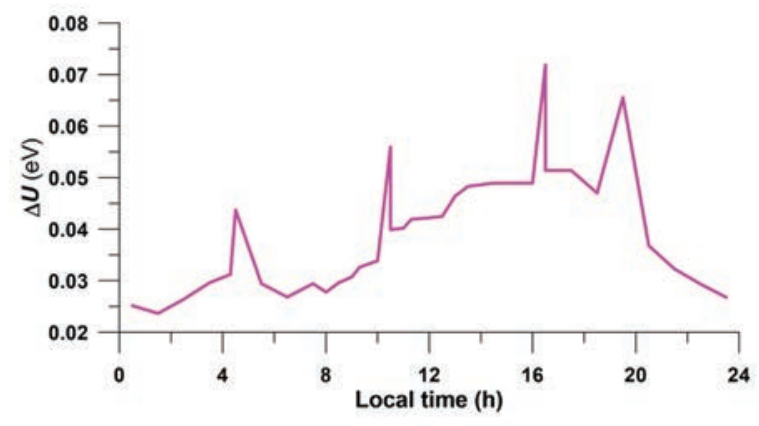

Figure 6. A) variations of relative air humidity on 6 of August 2012 at Tabriz station (Iran); B) variations of dew point temperature on 6 of August 2012 at Tabriz station (Iran); C) variations of correction to the water vapor chemical potential $\Delta U$ on 6 of August 2012 at Tabriz station (Iran). 
spot). It is interesting to note that usually LCA indicate by one its ends to the earthquake epicenter position what we have in the present case.

We can mark the synchronism in space and time of all three types of atmospheric anomalies, and looking at the temporal dynamics we can also note that LCA appeared the latest.

Next case we analyzed (East Azerbaijan double shock) was the smaller magnitude earthquake practically in the same geographical area. Again we collected three parameters demonstrated for the first case: $\Delta U, \mathrm{AOT}$ and LCA. $\Delta U$ temporal variation is shown in the Figure 5.

In the case of East-Azerbaijan earthquake the main shocks happened not after the end of $\Delta U$ increase but in the middle of the long lasting (near 10 days) maximum, approximately 5 days after the start of the $\Delta U$ growth. To explain this we made more detailed analysis using not only the daily average values of the temperature and humidity but also the raw daily variations and detected that the monthly maximum of $\Delta U$ was reached on 6 of July. These data are shown in the Figure 6.

We used 3 parameters: relative air humidity (Figure 6A), dew point (Figure 6B) and $\Delta U$ (Figure 6C). The sharp drops of relative humidity demonstrate the intensity of condensation process due to IIN (Figure 6A), humidity reaches incredible value $4 \%$. The same story with dew point (Figure 6B): near 07PM it reaches $-11^{\circ} \mathrm{C}$, it is on 6 of July with the daytime temperature near $37^{\circ} \mathrm{C}$ ! This fact also demonstrates the incredibly low relative air humidity. $\Delta U$ shown in Figure $6 \mathrm{C}$ reached its absolute monthly maximum near 04 p.m., and one can see that its value exceeds $0.07 \mathrm{eV}$, essentially higher than in Figure 5 shown for daily averages (maximum is slightly higher than $0.04 \mathrm{eV}$ ). From this comparison we can conclude that radon activity continued after the main chocks on 11 of August during the aftershock period, and even increased in average, but extremely strong sporadic splashes took place on 6 of August leading to very high levels of ionization and consequent water vapor condensation leading to monthly minimum at 07 p.m.. From this analysis we can conclude that the most anomalous day when the monthly maximum of $\Delta U$ was reached is 6 of August, 5 days before the main shocks.

AOT variations for East Azerbaijan double shock shown in the Figure 7 are very similar to those for Van earthquake. The maximum of AOT is observed on 7 of July, 4 days before the main shock.

In the Figure 8 the satellite image taken by TERRA/MODIS on 8 of August at 0730 UT (1030 LT) is shown.

As in the first case we observe the synchronism in time and space of all three types of anomalies, with some differences in the $\Delta U$ variations (longer period in the second case). And again the LCA shows up the last in the time sequence.

The third case, Virginia earthquake, had the lowest magnitude from all three cases but because its close proximity to the capital of United States, it attracted a lot of attention. This case is interesting also because of the cli- mate difference (dry weather in Western Turkey and Iran against the wet weather in East cast of United States).

In Figure 9 the $\Delta U$ derived from the Richmond meteorological data is shown. One can observe the double peak increase of $\Delta U$ starting from 16 of August with local maximum on 18 of August, and the second maximum at the day of earthquake on 23 of August. Contrary to first two cases these local maxima are not the largest in August, we can observe another one, stronger during 9-12 of August.

The closest point of AERONET network to the Virginia earthquake epicenter was in Greenbelt, Maryland (station SERC) (Figure 10). We see the maximum of AOT registered on 19 of August, 4 days before the earthquake.

And the last parameter to be presented for the case of Virginia 2011 earthquake is the LCA registered by TERRA/MODIS on 22 of August (Figure 11). ${ }^{10}$ A day before the earthquake there appeared a mesh of cloud stripes over the state of Virginia, USA. Against its background, two wider clearance canyons showed up, joining at wide angle. And as in two previous cases the end of LCA is very close to the earthquake epicenter.

Comparing all three parameters for the Virginia earthquake case we can mark that $\Delta U$ starts to increase 8 days before the main shock (the first maximum lasting from 7 to 12 of August is associated with thunderstorm activity as it was mentioned above), has two peaks with principal one at the day of seismic shock, AOT has maximum 4 days before the seismic shock, and LCA - one day before the seismic

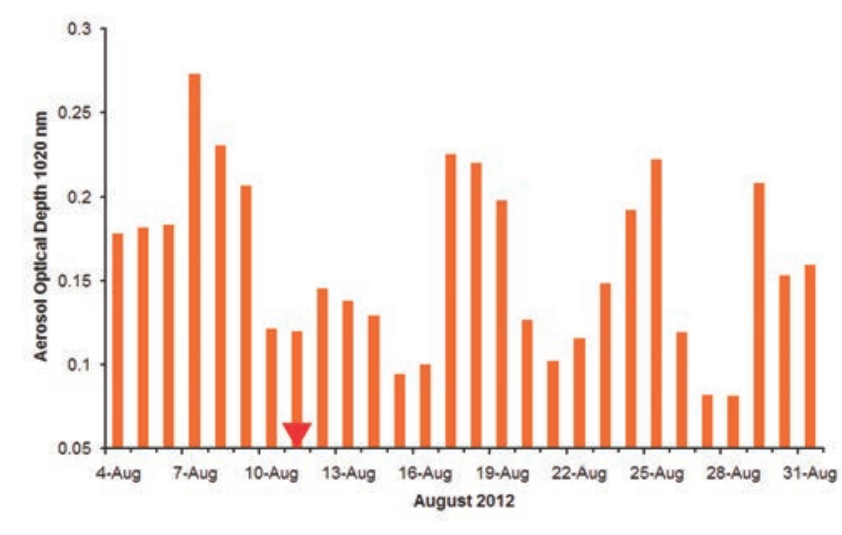

Figure 7. Aerosol optical thickness at the wavelength $1020 \mathrm{~nm}$ measured at AERONET IASBS station, August 2012.

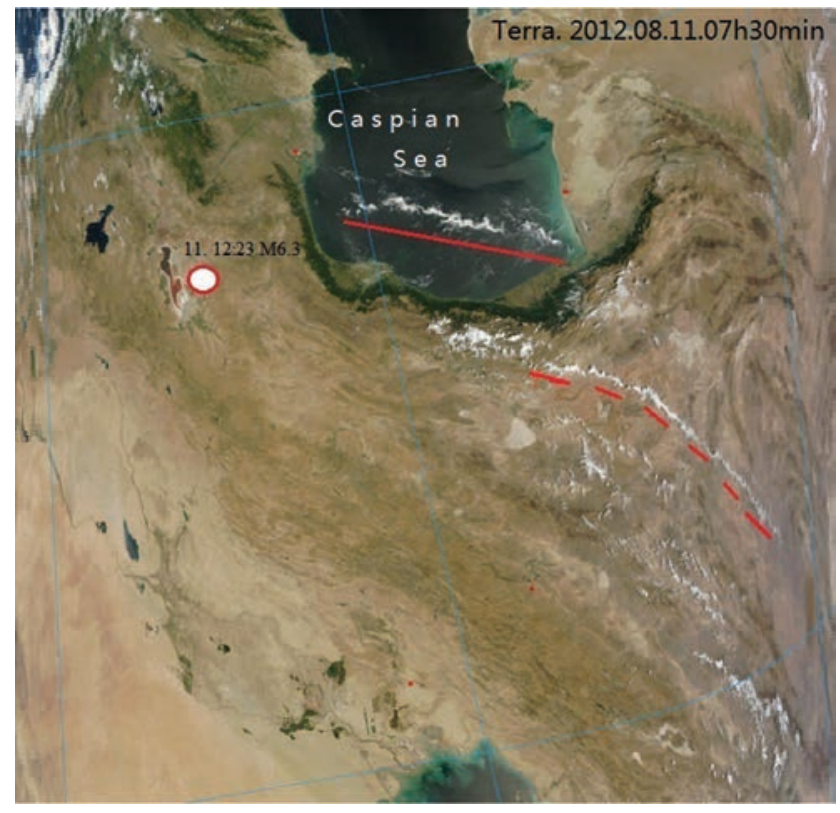

Figure 8. Linear cloud anomalies (marked by red lines) registered on 8 of August 2012. Earthquake epicenter position is shown by white circle. 


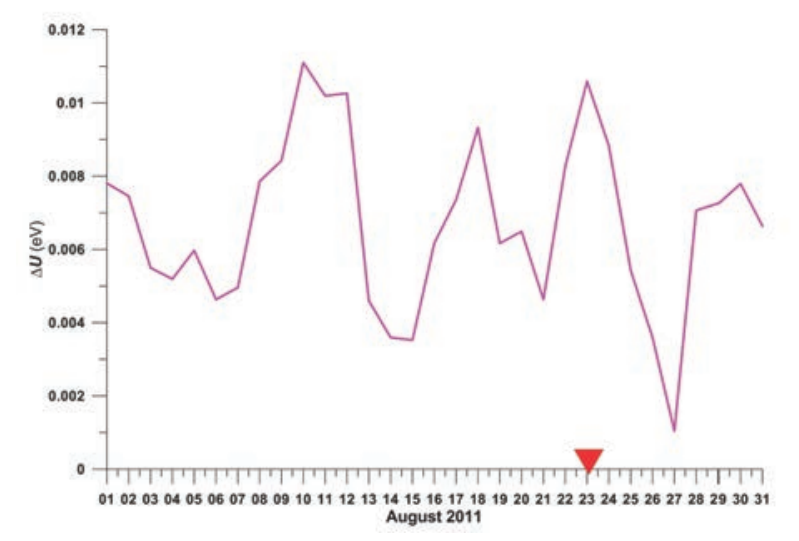

Figure 9. $\Delta U$ temporal variation for August 2011 at Richmond, Virginia, USA.

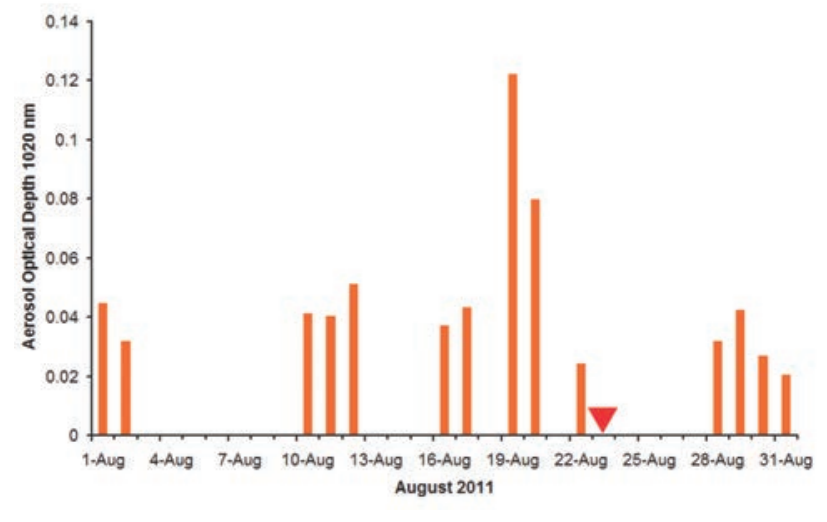

Figure 10. Aerosol optical thickness variations at station SERC for August 2011.

shock. As in two previous cases the LCA is the latest one in time sequence.

\section{Discussion}

Comparing three different cases of earthquakes with the magnitudes $7.1,6.4$, and 5.8 we investigated behavior of three atmospheric parameters which meaning is described above. All cases have very strong similarity, especially, in their synchronous emerging in space and time. As concerns the spatial characteristics the most similarity we observe in LCA structure: the end of the LCA is very close to the impending earthquake epicenter position (looks like LCA indicates the epicenter position). Other important feature is that the cloud structure always appears after the maximum of aerosol concentration, what supports the idea that just these aerosols are responsible for the LCA formation, and show the process development from the ground surface up to the upper layers of troposphere. We can indicate one important thing that with decrease of earthquake magnitude the leading time of atmospheric anomalies emerging is shortening.

The major differences we observe in correction to chemical potential behavior, especially in the case of Virginia earthquake. We can consider two factors responsible for such variability: i) the climate in Virginia is more wet, and heat transform connected with the latent heat is more intensive there, especially after thunderstorms and heavy rains, what we observe on days 9-13 of August; ii) the intensity of radon variations is different in different areas of the globe, and it is weaker in Virginia than in Turkey or Iran. In addition, the magnitude of Virginia earthquake is smaller what implies also the smaller radon anomalies before this earthquake in comparison with first two cases. As a result the condensation heat due to radon activity is smaller than the condensation after rains.

\section{Conclusions}

We analyzed three different earthquakes with magnitudes from 7.1 till 5.8 with equal difference in magnitude value between them. Analysis of three different atmospheric parameters around the time of main shock within the area of earthquake preparation demonstrated the similarity of all parameters variations, their synchronism in time and space, what supports the idea of synergy of short-term earthquake precursors while approaching the system to the critical state - the moment of the main shock. Self-similarity (in this case we mean the pattern and temporal sequence of the observed atmospheric parameters variations) of the observed cases let us propose these atmospheric events to be used as shortterm earthquake precursors.

\section{References}

1. Mil'kis MR. Meteorological precursors of earthquakes. Izvestiya Earth Phys 1986;22: 195-204.

2. Dunajecka M, Pulinets SA. Atmospheric and thermal anomalies observed around the time of strong earthquakes in Mexico. Atmosfera 2005;18:233-7.

3. Pulinets SA, Ouzounov D, Ciraolo L, et al. Thermal, atmospheric and ionospheric 
anomalies around the time of the Colima M7.8 earthquake of 21 January 2003. Ann Geophys 2006;24:835-49.

4. Jing F, Shen XH, Kang CL, Xion GP. Variations of multi-parameter observed in atmosphere related to earthquake. Nat Hazards Earth Syst Sci 2012;13:27-33.

5. Ouzounov D, Pulinets S, Romanov A, et al. Atmosphere-ionosphere response to the M9 Tohoku earthquake revealed by joined satellite and ground observations: preliminary results. Earthquake Sci 2011;24:55764.

6. Pulinets SA, Ouzounov D, Karelin AV, et al. The physical nature of the thermal anomalies observed before strong earthquakes. Phys Chem Earth 2006;31:143-53.

7. Kathmann SM, Schenter GK, Garrett BC. Ion-induced nucleation: the importance of chemistry. Phys Rev Let 2005;94:116104.

8. Pulinets S, Ouzounov D. Lithosphereatmosphere-ionosphere coupling (LAIC) model - an unified concept for earthquake precursors validation. J Asian Earth Sci 2011;41:371-82.

9. Svensmark H, Pedersen JOP, Marsh ND, et al. Experimental evidence for the role of ions in particle nucleation under atmospheric conditions. Proc R Soc A 2006;463: 385-96.

10. Morozova LI. Clouds as forerunners of earthquakes. Sci First-hand 2011;4:80-91.

11. Pulinets SA. The synergy of earthquake precursors. Earthquake Sci 2011:24:535-8.

12. Boyarchuk KA, Karelin AV, Nadolski AV. Statistical analysis of the chemical potential correction value of the water vapor in atmosphere on the distance from earthquake epicenter. Issues Electromechan 2010;116:39-6.

13. Morozova LI. Crustal geodynamic activity: manifestations in cloud fields. Russian Geol Geophys 2012;53:416-23.

14. Guangmeng G, Jie Y. Three attempts of earthquake prediction with satellite cloud images. Nat Hazards Earth Syst Sci 2013;13:91-5.

15. İnceöz M, Baykara O, Aksoy E, Doğru M. Measurements of soil gas radon in active fault systems: a case study along the North and East Anatolian fault systems in Turkey. Radiation Measure 2006;41:349-13.

16. İnan S, Akgül T, Seyis C, et al. Geochemical monitoring in the Marmara region (NW Turkey): a search for precursors of seismic activity. J Geophys Res 2008;113:B03401.

17. Morozova LI. Satellite meteorological images as carriers of information on seismic processes. Geol Pac Ocean 2000; 15:439-46.

18. Dobrovolsky IR, Zubkov SI, Myachkin VI. Estimation of the size of earthquake preparation zones. Pageoph 1979; 117:1025-44. 